\title{
Probiotics and prebiotics in intestinal health and disease: from biology to the clinic
}

Article

Accepted Version

Sanders, M. E., Merenstein, D. J., Reid, G., Gibson, G. R. and Rastall, R. A. (2019) Probiotics and prebiotics in intestinal health and disease: from biology to the clinic. Nature Reviews Gastroenterology and Hepatology, 16. pp. 605-616. ISSN 1759-5053 doi: https://doi.org/10.1038/s41575-019-0173-3 Available at https://centaur.reading.ac.uk/85276/

It is advisable to refer to the publisher's version if you intend to cite from the work. See Guidance on citing.

To link to this article DOI: http://dx.doi.org/10.1038/s41575-019-0173-3

Publisher: Nature Research

All outputs in CentAUR are protected by Intellectual Property Rights law, including copyright law. Copyright and IPR is retained by the creators or other copyright holders. Terms and conditions for use of this material are defined in the End User Agreement.

www.reading.ac.uk/centaur 
Central Archive at the University of Reading

Reading's research outputs online 
Probiotics and prebiotics in intestinal health and disease: from biology to the clinic

Mary Ellen Sanders ${ }^{1}$, Daniel J. Merenstein ${ }^{2}$, Gregor Reid ${ }^{\beta}$, Glenn R. Gibson ${ }^{4}$ and Robert A. Rastall ${ }^{4}$

${ }^{1}$ International Scientific Association for Prebiotics and Prebiotics, Centennial, USA

2Department of Family Medicine, Georgetown University Medical Center, Washington, USA.

${ }^{3}$ Lawson Research Institute, and Western University, London, Ontario, Canada.

${ }^{4}$ Department of Food and Nutritional Sciences, The University of Reading, UK.

Correspondence to:

G.R Gibson.

g.r.gibson@reading.ac.uk

Abstract

Probiotics and prebiotics are microbiota management tools for improved host health. They target gastrointestinal effects via the gut, although direct application to other sites such as the oral cavity, vaginal tract and skin are being explored. Here, we describe gut-derived effects in humans. In the past decade, research on the gut microbiome has rapidly accumulated, accompanied by increased interest in probiotics and prebiotics as a means to modulate the gut microbiota. Given the importance of these approaches for public health, it is timely to reiterate factual and supporting information on their clinical application and use. In this Review, we discuss scientific evidence on probiotics and prebiotics, including mechanistic insights into health effects. Strains of Lactobacillus, Bifidobacterium, and Saccharomyces have a long history of safe and effective use as probiotics, but Roseburia spp., Akkermansia spp., Propionibacterium spp. and Faecalibacterium spp. show promise. For prebiotics, glucans and fructans are well proven with evidence building on prebiotic effects of other substances (e.g. oligomers of mannose, glucose, xylose, pectin, starches, human milk; and polyphenols). 
Key Points

- The human gut microbiota is integral to health and is associated with a variety of diseases

- Therapeutic and prophylactic effects of some probiotics and prebiotics for a variety of gut-related disorders might be, at least in part, mediated through modification of the microbiota and/or its function

- Probiotic microorganisms act via a variety of means, including modulation of immune function, production of organic acids and antimicrobial compounds, interaction with resident microbiota, interfacing with the host, improving gut barrier integrity and enzyme formation

- Prebiotics are substrates that are selectively utilized by host microorganisms conferring a health benefit; prebiotic effects include defence against pathogens, immune modulation, mineral absorption, bowel function, metabolic effects and satiety

- Use of some probiotics and prebiotics is justified by robust assessments of efficacy, but not all products have been validated; the goal is evidence-based use by healthcare professionals 


\section{[H1] Introduction}

When the Argentinian government requested of the Food and Agriculture Organization of the United Nations that an expert panel be formed to evaluate the health and nutritional properties of probiotics in food in 2000 , it precipitated the reemergence of a concept long part of human history. International recognition of the concept of probiotics, and coalescence around a definition of probiotic offered by this expert consultation, ${ }^{1}$ established an important consensus foundation.

The definition of probiotic decided by the consultation retained the essence of historical definitions offered over previous decades. It was intentionally broad, to encompass a wide variety of microorganisms, hosts, benefits, target sites and product types. It has stood the test of time and was reaffirmed, but grammatically corrected, in 2014 to the consensus definition of probiotics, which is: "live microorganisms that, when administered in adequate amounts, confer a health benefit on the host". ${ }^{2}$

Studies abound that describe how microbes are integrated into life processes and define ways that beneficial microorganisms - both commensal and externally applied-affect physiological homeostasis and host function. ${ }^{3}$ On the horizon is the promise of newly constructed recombinant strains and promising novel microbial species, which await testing in vivo. However, as these advances develop, we should recognize actionable evidence that is currently available. As will be discussed, convincing evidence exists for some established probiotics, which should be incorporated into health management. This incorporation includes complementary use with pharmaceutical agents, foods and lifestyle. Education of consumers, practitioners and regulators will facilitate appropriate use and point out needs for further research, which will hopefully include exploration of how to reach the individuals at greatest need with affordable and reliable probiotic products. ${ }^{4}$

Prebiotics, first defined in $1995^{5}$, have been used to manipulate microbes in the host to improve measurable health outcomes. An update to the prebiotic definition published in 2017 as "a substrate that is selectively utilized by host microorganisms conferring a health benefit" was compelled by the need to clarify what did and did not constitute a prebiotic substance in the face of scientific advances. ${ }^{6}$ The desire to optimize, for improved health, the microbial world associated with us has led to the development of compounds targeting an everexpanding group of microorganisms and benefits that are derived through them. No longer are prebiotics seen simply as boosters of the growth of bifidobacteria and 
lactobacilli, with recognition of their effects on system-wide metabolic and physiological readouts. ${ }^{6}$ Although the intestine remains the gateway to most of these effects, it is not an exclusive one. The extent to which prebiotics can affect microbial communities of the urogenital tract, oral-nasal areas and skin is now the subject of intensive exploration. ${ }^{7}$

This Review describes the current understanding of probiotic and prebiotic mechanisms of action, provides important examples of clinical studies on probiotic and prebiotic applications, and discusses current knowledge on mechanisms at the heart of these effects.

\section{[H1] Human gut microbiome}

The human gut is predominantly inoculated at birth. Microbial diversity develops as feeding and dietary patterns mature. It resembles the 'adult-like' microbiota after 3-5 years. ${ }^{8}$ Because of variations in $\mathrm{pH}$, substrate concentration, Eh (redox potential, activity of electrons) and transit time, microbial numbers vary between different anatomical regions of the gut. ${ }^{9}$ The stomach harbours fewer microbes than the small and large intestines. ${ }^{10}$ Studies using metagenomic approaches have highlighted the complex inter-relationship between our resident intestinal microbiota and mammalian metabolism. ${ }^{11}$ Through the process of fermentation, anaerobic gut bacteria metabolise substrates to form end products such as organic acids and gases. ${ }^{12}$ The main precursors for fermentations are dietary carbohydrates, proteins and lipids, as well as indigenous secretions such as mucin. This anaerobic metabolism contributes positively towards host daily energy requirements and homeostasis in the gut. ${ }^{13}$ Ideally, the human host lives in harmony with its complex gut microbiota in a state that promotes physiological resilience. ${ }^{14}$ However, dysbiosis can result from challenges such as medications, infections, ageing, lifestyle, surgery and poor nutrition, ${ }^{14},{ }^{15}$

In humans, a range of acute and chronic disorders can be a consequence of perturbation of gut microbial communities. ${ }^{16-18}$ On a chronic basis, inflammatory bowel disease (IBD), obesity and irritable bowel syndrome (IBS) have all been linked to intestinal bacteria and their activities. ${ }^{10}$ This aspect opens up the possibility of influencing the microbiota to reduce disease risk, fortify homeostasis and, in some cases, improve therapeutic status. Diet is a principal driver of gut fermentation and therefore can greatly influence functionality of the indigenous microbiota. ${ }^{19}$ Prebiotics 
are popular dietary approaches for modifying the gut microbiota to improve host health, ${ }^{6}$ as they are affordable, effective, safe and accessible.

\section{[H1] Probiotics}

As the concept of probiotics evolved over the past decades, the assumption was that their effects would be mediated through direct interaction with commensal microbiota. Some early definitions stipulated that probiotics functioned "by contributing to (the host's) intestinal microbial balance" 20 or "by improving the properties of the indigenous microflora". ${ }^{21}$ However, the current consensus definition of probiotics does not stipulate that probiotic effects are only microbiota-mediated, and indeed, other types of mechanisms are known. This idea that probiotics function in ways that might act beyond affecting the colonizing microbiota opens the door to a wider range of probiotic possibilities, encouraging innovation in the field.

Much of our knowledge on probiotic mechanisms is based on research using in vitro, animal, cell culture or ex vivo human models. Figure 1 compiles known mechanisms distributed among various probiotic strains. Not all mechanisms have been confirmed in humans nor do they exist in every probiotic strain. Although multiple mechanisms likely co-express in a single probiotic, the importance of any given mechanism will depend on many factors. For example, in an inflamed intestine, the ability to down-regulate inflammatory mediators and increase epithelial barrier function may be most important, ${ }^{22,23}$ whereas the ability to increase short chain fatty acids and hydration in the colon may be more important to normalizing intestinal motility. ${ }^{24}$

Research elucidating mechanisms of probiotics often relies on in vitro or animal studies. Probiotics are not unique in this regard. Animal studies have not always translated to humans; ${ }^{25}$ notable examples are probiotics for Crohn's disease and mental health function. ${ }^{26,27}$ Furthermore, inherent difference among probiotic strains exists, for example in the findings that one probiotic (in this case in conjunction with a prebiotic) significantly prevented sepsis in infants, ${ }^{28}$ whereas a different formulation failed to prevent necrotizing enterocolitis. ${ }^{29}$

The historic concept of 'colonization resistance, ${ }^{30}$ the situation whereby native gut microbiota occupy host tissues to exclude infection by potential pathogens (resident or invading), is another mechanism attributed to probiotics. ${ }^{31}$ Expression of colonization resistance is likely a sum outcome of the functioning of many of these different mechanisms in concert. Indeed, many host factors may impact the ultimate 
expression of health effects imparted by a probiotic, including properties of baseline microbiota. Although few data exist, one study tracking probiotic persistence in the gut was linked to properties of the baseline microbiota. Persistence of $B$. longum subsp. longum $\mathrm{AH} 1206$ in the human gut was predicted by low abundance in the host of $B$. longum and low microbial carbohydrate utilization genes. ${ }^{32}$ No clinical endpoints were tracked in this study, but the property of long-term persistence may contribute to physiological benefits. However, results of many different clinical trials that do not include stratification of subjects by baseline microbiota suggest that probiotic function is not necessarily predicated on a specific microbiota baseline. ${ }^{33,34}$ There may well be compositional patterns of microbiota that do not respond well to incoming probiotic strains, just as there are for certain drugs, ${ }^{35}$ but such profiles have not yet been fully defined.

[H3] Modulation of cell-mediated and humoral immune functions. Some probiotics have been shown to increase phagocytosis or natural killer cell activity and interact directly with dendritic cells (reviewed $\mathrm{in}^{36}$ ) Some also demonstrate the ability to upregulate antibody secretion translating into improved defences against pathogens and augmenting vaccine responses. ${ }^{37-39}$ Probiotic strains can increase levels of anti-inflammatory cytokines such as tumour necrosis factor with implications for abating colon cancer and colitis. ${ }^{10,36}$ As discussed later, cell-surface architecture, such as fimbriae, capsule and surface structures expressed by certain probiotics is a mechanistic driver for several of these activities.

[H3] Production of organic acids. Probiotic species belonging to the Lactobacillus and Bifidobacterium genera produce lactic and acetic acid as primary end-products of carbohydrate metabolism. These organic acids when produced in situ can lower luminal $\mathrm{pH}$ and discourage growth of pathogens as shown in various model systems. ${ }^{40-42}$ Lactobacillus and Bifidobacterium do not produce butyrate but through cross-feeding other commensal microbiota (for example, Faecalibacterium), levels of butyrate and other short-chain fatty acids in the gut can increase, potentially influencing many aspects of physiology, including the cardiometabolic phenotype. ${ }^{43}$ This phenotype can be derived from increased production of butyrate, correlating with improved insulin response, or abnormalities in propionate linked to type 2 diabetes. ${ }^{44}$ Based upon analyses of weight, lifestyle, metabolic measurements and short chain fatty acid (SCFA) levels, the risk of subjects developing cardiometabolic diseases can be calculated. ${ }^{45}$

[H3] Interaction with gut microbiota. Probiotic strains can interact with the gut microbiota through competition for nutrients, antagonism, cross-feeding and support 
of microbiota stability. ${ }^{46}$ Many probiotic strains are antagonistic toward other microbes, in part due to saccharolytic metabolism, which produces organic acids, but also by production of bacteriocins. ${ }^{47}$ These antimicrobial compounds can be active against pathogens at many sites including the human urinary tract and in the gut of humans or animals. ${ }^{48,49}$ Bifidobacteria produce acetate and can cross-feed other members of the gut microbiota (reviewed in ${ }^{50}$ ). Strains $B$. longum $\mathrm{AH} 1206$ and $B$. bifidum-ATCC15696 have been shown to persist in the infant gut, ${ }^{32,51}$ although in the latter case the concomitant decrease in pathogen abundance was not tested for a link to bacteriocin production. The ability of certain probiotic strains to improve eradication of Helicobacter pylori may involve some inhibition of the pathogen, but stronger evidence for probiotics in this context is for reducing side effects of antibiotics used in treatment. ${ }^{52}$

[H3] Probiotic-host interactions. Interactions of probiotic strains with host tissues are mediated by cell surface macromolecules, including proteins (surface layer associated proteins, mucin binding proteins, pili, and LPxGT-binding proteins) and non-protein components (lipoteichoic acid, peptidoglycan, exopolysaccharides). ${ }^{53}$ These structures have been shown to affect binding to intestinal and vaginal cells, mucin, and immune or dendritic cells resulting in increased transit times and improved barrier integrity (reviewed $\mathrm{in}^{53}$ ). An example of the different surface structures can be seen in the genome comparison of L. rhamnosus GG that uses pili to interact with the intestine and L. rhamnosus GR-1 with a unique cluster of exopolysaccharides to aid in vaginal activity. ${ }^{54}$

[H3] Improvement of barrier function. Primarily through studies in cell lines, several probiotic Lactobacillus and Bifidobacterium strains have been shown to increase expression of tight junction proteins (reviewed $\mathrm{in}^{55}$ ). A study using human intestinal epithelial enteroids and colonoids showed that $L$. rhamnosus GG pretreatment countered damage to tight junction zonula occludens 1 (ZO-1) and occludin (OCLN) caused by interferon-gamma. ${ }^{56}$ Another way in which probiotic strains may improve barrier function is through upregulating expression of mucus secretion genes, thereby reducing pathogen binding to epithelial cells. ${ }^{57,58}$. Downregulating inflammation is also regarded as a factor that improves barrier function. ${ }^{53}$ Of note, although some probiotic strains have the capacity to improve barrier function, this does not always occur in every cohort for reasons not yet fully understood. ${ }^{59}$

[H3] Manufacture of small molecules with local and non-local effects. Small molecules produced by certain probiotic strains have been described with different 
effects on the host and its microbiota. ${ }^{58}$ Perhaps one of the more intriguing findings is the production of neurochemicals such as oxytocin, gamma-amino butyric acid, serotonin, tryptamine, norepinephrine, dopamine and acetylcholine (reviewed in ${ }^{60}$, ${ }^{61,62}$ ) known to affect brain function. In a rat model of stress, L. helveticus NS8 feeding resulted in lower plasma corticosterone and adrenocorticotropic hormone levels and restored hippocampal serotonin and norepinephrine. ${ }^{63}$

[H3] Production of enzymes. Microbial enzymes such as $\beta$-galactosidase ${ }^{64}$ and bile salt hydrolase, ${ }^{65}$ which are produced and delivered by some probiotic strains, improve lactose digestion and blood lipid profiles in humans, respectively. In the case of Streptococcus thermophilus in yogurt, which facilitates lactose digestion, its predisposition to be permeabilized by bile when entering the small intestine promotes the delivery of microbial $\beta$-galactosidase to the small intestine to break down lactose into digestible glucose and galactose. ${ }^{64}$ This results in clinical benefit to individuals who are lactose intolerant. Indeed, the European Food Safety Authority considered evidence of this effect sufficient to authorize a health claim for $S$. thermophilus and $L$. bulgaricus as components of yogurt to alleviate symptoms of lactose maldigestion. ${ }^{66}$

Admittedly, cause and effect evidence of mechanisms in human hosts remains to be gathered, but technological advancements in genome sequencing and microbiome analyses, and surgical advances that allow real-time sampling in vivo, should help acquire elucidating data over the next few years.

\section{[H1] Prebiotics}

If we are to understand how prebiotics work, and more importantly exploit them to manipulate the microbiota to propagate health, then we need to keep in mind that microbes live in complex functional ecosystems. Within these, bacteria have a multitude of roles, including the conversion of incoming dietary carbohydrates, proteins and some fats into metabolites that can have either positive or negative effects upon host health. ${ }^{67,68,69,70}$. Current prebiotics are predominantly carbohydrate-based, but other substances such as polyphenols and polyunsaturated fatty acids may exert prebiotic effects. ${ }^{6}$ An example of polyphenols is water-insoluble cocoa fraction, shown in a gut model to significantly increase bifidobacteria, lactobacilli and butyrate production. ${ }^{71}$

Low molecular weight carbohydrates are very efficiently metabolised by microorganisms such as bifidobacteria, which possess a range of cell-associated and extracellular glycosidases and specific transport systems allowing them to rapidly 
assimilate low molecular weight sugars. ${ }^{72,73}$ Other microbes, such as members of the Bacteroides genus are adept at breaking down high molecular weight polysaccharides. ${ }^{74,75}$ Some bacteria might be regarded as keystone, having the ability to initiate breakdown of particular substrates $;{ }^{76}$ for example, Ruminococcus spp. can facilitate resistant starch degradation. ${ }^{77}$ Liberated low molecular weight dextrins are then metabolized by the microbial community. The pathway from a polysaccharide to a SCFA is thus a complex and indirect network of metabolism. Acetate and lactate, the main metabolic end products of bifidobacteria and lactic acid bacteria, are utilised by other microorganisms to produce, for instance, propionate ${ }^{78}$ and butyrate..$^{50,79}$ Likely ecological networks involved in the metabolism of carbohydrates have been elucidated, ${ }^{74,80,81}$ although the extent to which they operate in the gut is not clear at the present time.

A further complication in studies of the ecosystem response to carbohydrates is that it is heavily influenced by the microorganisms that are already present. It has become clear that individual microbiomes that are Prevotella-dominant can ferment carbohydrates more rapidly than can Bacteroides-dominant microbiomes. ${ }^{82}$ Furthermore, when these distinct faecal inocula, dominated by Prevotella or Bacteroides, were incubated with prebiotic fructo-oligosaccharides (FOS) or with two different arabinoxylans, the profile of SCFA produced was distinctly different and correlated with the microbiome. ${ }^{83}$ Cultures using Prevotella-dominant inocula produced significantly higher ratios of propionate to acetate and butyrate than the Bacteroides-dominant microbiotas. A similar influence of starting microbiome composition on carbohydrate fermentation has been seen using isomaltooligosaccharides as a carbon source in an in vitro batch fermentation model with human microbiota. ${ }^{84}$

Microbiome studies based on 16s rDNA sequencing have given rise to an increased awareness of the richness of the gut microbial ecosystem ${ }^{85}$ and, in some cases, to associations between certain microorganisms or microbiome profiles and disease states. These include IBD, ${ }^{86}$ type II diabetes mellitus, ${ }^{87-89}$ IBS ${ }^{90,91}$ and obesity. ${ }^{92,93}$. These profiles have frequently been termed "dysbioses", although it is not currently possible to define such a state as 'normobiosis' or a 'normal' microbiota Such associations tend to be merely the starting point for investigation into the role of specific microorganisms in disease. Sequencing studies do not give us an understanding of the functional interactions between members of the gut microbiota and it is imperative that this functional ecology is studied in more detail. It is becoming clear that although there might be a huge diversity of individual taxa in the gut 
microbiomes of individuals, there is a high level of functional redundancy, and specific ecological functions are provided by a range of bacteria across different individuals, ${ }^{94,95}$.

Given that we have an imperfect understanding of the functional ecology of the gut microbiota, uncovering the mechanisms of action of prebiotics presents a challenge. Despite this issue, we can postulate probable mechanisms by which a prebiotic can lead to health benefits. These pathways are presented in Figure 2 and discussed herein. All of these postulated mechanisms have support from research carried out through in vitro or animal models, although in many cases, establishing that they actually occur within human gut microbiota is difficult.

[H3] Defence against pathogens. Although mechanistically challenging to establish in humans in vivo, pathogen defence can be investigated in vitro using model systems. ${ }^{96,97}$. As noted for probiotics, production of organic acids through prebiotic administration and propagation of beneficial bacteria will result in a reduction in luminal $\mathrm{pH}$, inhibiting growth of pathogens. Establishment of a stable population of commensal microorganisms will reduce nutrient availability for invading microorganisms, inhibiting colonisation. In studies of elderly individuals, 10 weeks of daily galactooligosaccharide (GOS) intervention induced increases in immune function, notably enhanced phagocytic activity and activity of natural killer cells. ${ }^{98,99}$.

[H3] Immune modulation. Although exact mechanisms are unclear, there is evidence that prebiotic intervention can reduce type $2 \mathrm{~T}$ helper responses and thus affect allergy. The most supportive data come from studies in infants. Galacto- and long chain fructo-oligosaccharides in infant formula administered in a double-blind, randomized, placebo-controlled trial of 259 infants, showed reduced incidence of atopic dermatitis, wheezing and urticaria to less than $50 \%$ of the incidence in nonprebiotic formula fed infants. ${ }^{100,101}$ In a prospective, double blind, placebo-controlled fashion, not as yet replicated, healthy term infants at risk of atopy fed prebioticsupplemented hypoallergenic formula for 6 months had a greater than five-fold reduction in prevalence of allergies five years after feeding. ${ }^{102}$

[H3] Increased mineral absorption. Most absorption of minerals takes place by active transport mechanisms in the small intestine, ${ }^{103}$ Scavenging calcium could make a substantial positive contribution to health. As already discussed, fermentation of prebiotics leads to production of SCFA, which reduces luminal $\mathrm{pH}$. This drop in $\mathrm{pH}$ can increase calcium solubility, thereby providing a greater driving force for passive uptake. A problem with proving this is that many calcium salts in supplements and 
food have $\mathrm{pH}$-dependent solubility and limited availability, and depending on the starting $\mathrm{pH}$, solubility of calcium can actually increase with higher $\mathrm{pH} .{ }^{104}$

Studies have shown that consumption by young adolescents of a mixture of FOS and inulin ${ }^{105,106}$ or GOS $^{107}$ can result in marked increases in absorption and calcium mineralised into bone. Such early intervention may reduce incidence of osteoporosis in later in life. This hypothesis is supported by animal model data ${ }^{108}$, but long-term studies in humans are lacking.

[H3] Improved bowel function. Improvements in bowel function have often been ascribed to simple faecal bulking by consumption of dietary fibre. However, animal studies have shown that SCFAs produced by fermentation of prebiotics can regulate gut hormones that in turn modulate the local motor responses of the gut ${ }^{109,110}$. The humectant water binding capacity of prebiotic carbohydrates also has the effect of softening stools, making passage easier. ${ }^{111,112}$

There are surprisingly few studies on the effect of prebiotics on bowel function, although they have consistently led to improvements in stool consistency and defecation frequency in randomized trials ${ }^{113,114}$

[H3] Metabolic effects. As discussed earlier, prebiotic intervention results in the elaboration of SCFAs that can act to improve barrier function in the gut and prebiotic intervention with GOS has shown improvements in barrier function in vivo. ${ }^{115}$ Impaired barrier function can allow translocation of inflammatory mediators such as bacterial lipopolysaccharide (LPS) from the gut into systemic circulation, which has been termed metabolic endotoxaemia ${ }^{116}$ and has been suggested to be a causative factor in diabetes and obesity according to evidence, albeit from studies in mice. ${ }^{117,}{ }^{118}$.

Metabolic effects of prebiotics have been subject to several metaanalyse ${ }^{119,120,121,122}$ and although the results among studies vary, the general consensus is that prebiotic intervention has a positive effect on glucose homeostasis, inflammation and blood lipid profile in humans. Although interventions with GOS ${ }^{123}$ and inulin ${ }^{124}$ have shown improvements in inflammatory markers in individuals with obesity, these have been relatively short-term studies over a few months and the effect on metabolic health over a long period of consumption is yet to be established.

The hypothesis underlying much research on prebiotics and barrier function and inflammation is that fermentation products such as SCFA probably mediate the beneficial effects through mechanisms discussed above. However, it has been shown that, at least in vitro, GOS can directly stimulate the expression of tight junction proteins in intestinal epithelial cell lines and decrease trans-epithelial flux ${ }^{125,126}$. Given 
that GOS is fermented in the gut, however, the extent to which such mechanisms act in vivo are unclear at present.

It is possible that the effect of inulin in improving glycaemic response could be due to direct inhibition of the intestinal isomaltase-sucrase enzyme complex, but so far the evidence is only from mouse studies ${ }^{127}$. Identification of direct mechanisms from metabolic mechanisms in humans is, however, extremely difficult.

[H3] Effect on satiety. SCFAs produced by fermentation in the gut can interact with specific fatty acid receptors, FFAR2 and FFAR3 and regulate lipolysis and release of the incretin glucagon-like peptide-1. ${ }^{28,129}$ These receptors are found on many tissues and could be a key mechanistic link between prebiotic fermentation and systemic health benefits. SCFAs can regulate appetite via several mechanisms, ${ }^{130}$ with studies showing that the interaction between SCFA and colonic L-cells results in production of anorexigenic hormones such as PYY and GLP-1. Other examples are SCFAs surviving metabolism by colonic epithelial cells can reach the liver via the hepatic portal vein where propionate stimulates gluconeogenesis, acting as a satiety signal. ${ }^{131}$ SCFAs entering the circulation could also interact with FFAR2 and FFAR3 located on adipose tissue, resulting in leptin stimulation. According to a study in mice, acetate, the principal SCFA formed by prebiotic fermentation, can cross the blood-brain barrier and enter the hypothalamus, promoting anorectic signals. ${ }^{132}$

\section{[H1] Translation to the clinic}

Box. Overcoming barriers to translation to the clinic

- More high quality, adequately powered randomized, controlled trials that test well-defined probiotic (strain or strain combinations, dose, delivery matrix) and prebiotic interventions on substantive clinical outcomes.

- Better tracking of safety data during the conduct of short and long term clinical trials

- Improved availability of high quality, properly labelled, and effective commercial products $^{133}$

- Application by clinicians of available efficacy data in evidence-based manner. This comprises assessment of totality of data (positive and null) through unbiased systematic review processes for specific probiotic and prebiotic interventions.

- Better understanding of characteristics of host (including diet, baseline microbiota, medications and disease) that improve response to probiotics or prebiotics

- Clinicians need clarification about probiotic and prebiotic products: are they safe, who will benefit - how and to what extent, and can the product labels be trusted 
Many clinical gastrointestinal indications could benefit from probiotic and prebiotic interventions. In the case of prebiotics, a link between the clinical benefit to microbiota function should be established. For probiotics, a clinical indication is needed. For both, robust product information is required ${ }^{133}$.

There are clinical indications for use of certain probiotic strains supported by robust evidence. In paediatric and/or adult populations, evidence exists for necrotizing enterocolitis (NEC), ${ }^{134}$ antibiotic-associated diarrhea (AAD) and $H$. pylori infection ${ }^{135,136,137}$, defecation frequency ${ }^{138,139}$, infantile colic, ${ }^{140}$, mild to moderate ulcerative colitis, ${ }^{141}$ irritable bowel syndrome, ${ }^{142}$ treatment of acute diarrhea ${ }^{143}$ prevention of $C$. difficile-associated diarrhea ${ }^{144}$ and neonatal sepsis. ${ }^{28} \mathrm{~A}$ recent metaanalysis provided evidence that probiotic use has the potential to decrease antibiotic utilization in children. ${ }^{145}$ Some clinical guidelines have been issued for probiotic use in children. ${ }^{146,147}$ Systemic from the gut, evidence exists for reduction of incidence and duration of upper respiratory tract infections. ${ }^{147,149}$ No official recommendations have been made for adult uses of probiotics. Additional research clarifying the most effective strains and doses is needed for many clinical targets so far researched. ${ }^{150,151,152}$ Although many clinical indications are promising, data are still emerging for endpoints including brain, metabolic, and cardiovascular effects.

Generally, the strength of evidence for prebiotic interventions lags behind those for probiotics. Perhaps the strongest support for prebiotic use comes from prebiotic infant formulae. Such products are now routinely supplemented with mixtures of GOS and fructans ${ }^{153,154}$ and this blend of prebiotics in a 9:1 ratio reduced respiratory tract infections to levels found in breast-fed infants. ${ }^{155,156} 101$ There is less evidence that prebiotics can reduce infections in adults, although one placebocontrolled, randomized, double blind study of 159 healthy volunteers, showed that GOS could reduce the incidence of diarrhea. ${ }^{157}$

Much of the research focus on prebiotics has been in the realm of functional food (improves well-being through benefit beyond its nutrient content) applications. The one example of a prebiotic food application recognized by European regulatory authorities is on improved bowel function in healthy adults resulting from consumption of $12 \mathrm{~g}$ of chicory inulin per day. ${ }^{158,159}$

Prebiotic foods designed to increase satiety and reduce energy intake is a promising approach to augment compliance with weight loss diets. Oligofructoseenriched inulin in overweight children has been shown to increase satiety, reduce energy intake as well as BMI and body fat mass over 16 weeks (body weight 
decrease of $3.1 \%$, percent body fat decrease of $2.4 \%$ compared with children given placebo (increase of $0.5 \%$, increase of $0.05 \%$ respectively). ${ }^{160,161}$ Oligofructose ingested daily by 29 adults for 12 weeks in a granola bar formulation, reduced by 0.3 (sd 1.2) $\mathrm{kg}$ lean mass and waist circumference by $-2.2(\mathrm{sd} 3.6) \mathrm{cm}$, with a concomitant intake and increase satiety in adults over a 12-week intervention. ${ }^{162}$ However, not all studies have suggested benefits. One study of 97 overweight or obese children given oligofructose for 12 weeks did not show a statistically significant change in BMI-for-age z-score versus placebo. ${ }^{163}$ This study did not measure the effect of the prebiotic on the gut microbiota and its function, which would have provided mechanistic insight to better understand the null study results and enabled better design of future interventions.

The replacement of glycaemic carbohydrates in food products with nonglycaemic carbohydrates to reduce post-prandial glycaemic responses has already received a positive EFSA opinion. ${ }^{164}$ Prebiotic carbohydrates might be expected to bring additional benefits in terms of increasing satiety in such a replacement strategy. Promising results were observed from a double-blind, randomized, controlled crossover trial of 40-42 healthy adults who consumed a yogurt drink containing oligofructose. The intervention improved postprandial glucose responses. ${ }^{165}$

There is now some evidence that the stool microbiota profiles of patients with inflammatory conditions, such as inflammatory bowel disease, differs from those who are heathy, ${ }^{166}$ but it is not clear at the present time why. It is unclear whether these differences are caused by the underlying medical condition, are a consequence of the disease pathology, or due to confounding factors such as medications or altered dietary habits. Probiotic or prebiotic interventions hold promise to achieve disease or symptom mitigation through microbiota modulation. An understanding of the microbiome composition and function in the donor and recipient will help us understand the extent to which clinical success depends on these factors. ${ }^{167}$ Indeed, some clinical trials have noted the importance of baseline microbiota composition among responders. ${ }^{168,169,170}$ Microbiota patterns can be influenced by lifestyle, living conditions, diet, medications and stool consistency, among other transient variables. Advanced age is also thought to be a factor, but one study of Chinese subjects has shown that healthy centenarians have similar microbiota to healthy young people, ${ }^{171}$ suggesting that factors other than age are more important drivers of microbiota composition. Furthermore, research methodologies and data management may lead to spurious interpretations of microbiota assessments, which has the potential to mislead. ${ }^{172}$ Although clinical benefits have been observed with probiotic and prebiotic 
interventions, the onus is on researchers to clarify the role of the microbiome in these successes to optimize short and long-term outcomes. ${ }^{173,174,175,176,177 .}$

Careful phenotypic and genotypic descriptions of study subjects may also be important to clinical trial success targeting the microbiome. Host genetic studies may help, for example, in the microbiome-mediated disease of IBD, where 163 loci were identified to meet genome-wide significance thresholds. ${ }^{178}$ However, since the majority of cases of IBD are not the result of a single host gene defect, ${ }^{179}$ complicating the development of clinical interventions based on host genetics. Another complication is that identified genes constitute risk factors, not causal determinants, for a disease, and therefore clinical strategies based on host genomics have not been forthcoming.

IBD comprises two main forms, Crohn's disease and ulcerative colitis. In Crohn's disease, there seems to be distinct molecular subclasses of genomic associations, further complicating development of effective strategies. ${ }^{180}$ This may in part explain why probiotic strains have mostly failed to be effective in improving the management of Crohn's disease. ${ }^{181,182}$ The reason why mild to moderate ulcerative colitis has been somewhat improved by probiotic intervention ${ }^{183}$ but Crohn's is not known. The future success of microbiota manipulation to mitigate serious inflammatory conditions will require an understanding of the interactions between the microbiome and the human genetic risk factors and will necessitate moving beyond microbial genomic sequencing to transcriptomic, metabolomic and proteomic investigations.

The promise of treating or curing disease with microbiota manipulation continues to be explored using probiotic species different from those traditionally employed ${ }^{184}$. Many probiotics in current use are from the genera Lactobacillus and Bifidobacterium. Although many of them were derived from the faeces or intestinal mucosa of healthy human subjects, researchers today are considering the utility of many newly explored human resident microbes, such as Akkermansia, Eubacterium, Propionibacterium, Faecalibacterium and Roseburia. This will require going beyond laboratory animal experiments that proliferate in the literature. ${ }^{185,62}$

Faecal microbial transplantation (FMT), which has been a reasonably successful treatment for recurrent Clostridium difficile infection, ${ }^{186,187,188}$ is being met with mixed success in the treatment of other conditions ${ }^{189-191}$. Although FMT is not a probiotic application since it is not suitably defined microbiologically to meet the probiotic definition, ${ }^{2}$ the approach is based on the concept that microbes derived from healthy donor feces can restore proper function to a dysbiotic microbial 
ecosystem. It is noteworthy that there have only been a few blinded, randomized controlled trials (RCTs) on FMT for treatment of recurring $C$. difficile, and these have been relatively small studies and we have little information on the long-term changes that such a broad, poorly defined and non-specific treatment might have on individuals. A well-defined reproducible probiotic intervention is more suitable for rigorous research investigation and could be safer long-term than FMT, as suggested by several researchers attempting to assemble a defined consortium of microbes for such purposes ${ }^{192}$. Whether these defined consortia, typically comprising many human commensal microbial species, can reach the same levels of cure as FMT remains to be seen.

The potential impact of gut microbiota manipulation on clinical medicine is promising. However, in the excitement over potential, stakeholders often forget that association does not mean causation. For example, blinded reviews of 34 oesophageal biopsy samples found that these microbiomes could be classified into 2 types. Type I was dominated by the genus Streptococcus and was phenotypically normal. But Type II, demonstrating a greater proportion of Gram-negative anaerobes and/or microaerophiles, correlated with oesophagitis and Barrett oesophagus. ${ }^{150}$ Like many other microbiome findings, this does not prove causation and there are numerous potential reasons why these associations might exist, including diet, drugs, and lifestyle. One hypothesis might be that administering a safe, select Streptococcus could reduce oesophagitis and Barrett's oesophagus, but this has not been tested. Microbiome differences do not necessarily mean that microbiota modification will lead to improved health.

\section{[H1] The future}

The gut microbiota might be central to the cause of many disorders and its modulation could hold the key to new effective therapies. So, what are the roles of probiotics and prebiotics? In a general sense, both interventions serve to increase the community of beneficial microorganisms and products of their growth and metabolism in the host. In this context, effects relayed might exert influences systemically, such as in the cardiovascular system, or to the urogenital tract, skin and brain. ${ }^{193}$

The field is poised for conceptual advances. Target microbes will expand beyond the typical Bifidobacterium spp. and Lactobacillus spp. (as mentioned above) 
to include other genera and maybe more yeast species. ${ }^{194-197}$ These microorganisms might be new probiotic candidates or further targets for prebiotic utilization.

Improved precision, accuracy, and repeatability of measures of microbial composition, which lead to genuine and not misleading interpretations, are needed in this field. ${ }^{172}$ Improved assessments will lead to an expanded range of probiotic and prebiotic products. For example, propionate and butyrate are both considered to be beneficial gut microbial metabolites, but neither is produced by bifidobacteria or lactobacilli. ${ }^{198,199}$ Therefore, an opportunity exists to define microbes with metabolic capabilities beyond those afforded by traditional probiotics.

Another development could be anti-adhesive molecules and carbohydrates that attenuate microbial virulence. These factors would be adjuncts to current prebiotic approaches in that they are not selectively utilized substrates.

To have robust proof that gut microbiome alterations can reduce disease incidence or mitigate disease, more well-designed RCTs are needed. By randomly assigning individuals to intervention groups, most biases are reduced and the chances of useful results are improved. Due to the easy availability and relatively cheap cost of high-throughput sequencing technology, microbiota analysis is becoming widespread and differences among disease states increasingly well publicized. The expertise and databases required for metabolomic analysis is also on an upward trend. This will be vital to optimise clinical translation, as a much greater awareness of the functional ecology of the gut is needed together with improved clarity of how this ecosystem influences systemic health. Microbiota and host transcriptomic studies are also important, but they are expensive, time-consuming and require substantial bioinformatic support. Ultimately, the application of probiotic and prebiotic regimens has the potential to improve human health and contribute greatly to how patients are managed and/or disease risk is reduced.

\section{[H1] Conclusions}

Although certain commonalities allow us to group substances under the 'probiotic' or 'prebiotic' umbrellas, benefits to human health are tied to specific products, not the categories en masse. To the extent that a clinical outcome is associated with a specific mechanism of action, then it could be hypothesized that a similar strain or prebiotic expressing that mechanism might also be beneficial. However, it is important not to overgeneralize conclusions about specific entities. In general, when an intervention is effective or ineffective, it must be recognized that those results are tied to specific formulations, doses, clinical endpoints and target populations. It is 
incumbent upon responsible scientists to consider the totality of available information on specific interventions as a basis of overall conclusions on effectiveness.

Furthermore, clinicians should scrutinize both positive and null studies for bias, as only in eliminating bias in research will we move the field toward truth, thereby realising the potential of probiotics and prebiotics.

The body of research suggests that these interventions can not only improve symptomology, but have a meaningful effect on reducing pathology and even saving lives. The prevention of sepsis and NEC in infants provides compelling examples. These findings demonstrate effective translation of human microbiome research. Such clinical impact has changed practice in many healthcare environments. Yet many constituencies have yet to embrace the concept through critically considering the strengths and weaknesses of existing data.

In developing countries, probiotics widely available in developed countries are either not accessible or affordable to most people. However, a program has introduced inexpensive sachets containing a probiotic L. rhamnosus (GR-1 or Yoba 2012) plus $S$. thermophilus $\mathrm{C} 106$ that allows locals to produce different forms of fermented foods (yoghurt, millet, cereals, juices) that not only influence health but also empower poverty-stricken communities to improve social well-being. ${ }^{4}$ With over 260,000 consumers being reached each week in East Africa, the potential is enormous to use these beneficial microbes and local food sources to impact communities (manuscript submitted).

Diseases and poor health often result from the interplay of microbiological and biological ecosystems along with societal issues including pollution, food shortages and poor medical care. ${ }^{200,201}$ We encourage more research and translational efforts on probiotics and prebiotics to serve the people of developing countries, who might stand to benefit most from these interventions.

\section{Author contributions}

The authors contributed equally to all aspects of the article.

\section{Competing interests}

The authors declare no competing interests.

\section{Publisher's note}


Springer Nature remains neutral with regard to jurisdictional claims in published maps and institutional affiliations.

\section{Reviewer information [Au: placeholder for reviewer information as per our Referee accreditation rules]}

Nature Reviews $X X X$ thanks [Referee\#1 name], [Referee\#2 name], and other anonymous reviewer(s), for their contribution to the peer review of this work.

\section{Key References:}

1. Gibson, G.R., et al. Expert consensus document: The International Scientific Association for Probiotics and Prebiotics (ISAPP) consensus statement on the definition and scope of prebiotics. Nature Rev. Gastroenterol. Hepatol. 14(8), 491-502. doi: 10.1038/nrgastro.2017.75 (2017).

Comment: ISAPP prebiotics consensus that looked at its definition, evolution, uses, types and health attributes.

2. Hill, C. et al. Expert consensus document: The International Scientific Association for Probiotics and Prebiotics consensus statement on the scope and appropriate use of the term probiotic. Nature Rev. Gastroenterol. Hepatol. doi: 10.1038/nrgastro.2014.66 (2014). Comment: ISAPP probiotics consensus that looked at its definition, evolution, uses, types and health attributes.

3. Klaenhammer, T. R., Kleerebezem, M., Kopp, M.V. \& Rescigno, M. The impact of probiotics and prebiotics on the immune system. Nat. Rev. Immunol. 12(10), 728-734 (2012).

Comment: four experts discuss probiotics, prebiotics and immunity then provide their thoughts on the future application as a disease therapy.

4. Qin, J. et al. A human gut microbial gene catalogue established by metagenomic sequencing. Nature. 464(4), 59-65 (2010).

Comment: definition and description of the minimal gut metagenome and bacterial genome in terms of functions. 
5. Reid, G. et al. How do probiotics and prebiotics function at distant sites? Ben. Microbes 8 (4), 521-533 (2017).

Comment: ISAPP working group that looked at how early life microbiome programming influences the gut microbiota communication with distant sites e.g. airways, heart, brain and metabolism.

6. Rook, G., Bäckhed, F., Levin, B.R., McFall-Ngai, M.J. \& McLean, A.R. Evolution, human-microbe interactions, and life history plasticity. Lancet. 29 (390), 521-530 (2017).

Comment: discusses how some microbes have co-evolved with humans and play crucial roles in host physiology and metabolism, whereas others are intrusive.

7. Thursby, E. \& Juge, N. Introduction to the human gut microbiota. Biochem. J. 474(11), 1823-1836. doi:10.1042/BCJ20160510 (2017).

Comment: current understanding of the development and composition of the human gut microbiota, and its impact on gut integrity and host health.

8. Yatsunenko, T. et al. Human gut microbiome viewed across age and geography. Nature 486, 222-227 (2012).

Comment: consideration of the gut microbiome when evaluating human development, nutritional needs, physiological variations and the impact of westernisation.

Probiotics and prebiotics in intestinal health and disease: from biology to the clinic

Mary Ellen Sanders, Daniel J. Merenstein, Gregor Reid, Glenn R. Gibson and Robert A. Rastall

The gut microbiota has been implicated in a range of diseases with microbiota manipulation suggested as a possible therapeutic approach. This Review describes current understanding of probiotics and prebiotics as a means to manage the microbiota to improve host health, including mechanisms of actions and potential for clinical use. 
Figure 1. Probiotic mechanisms of action. Diverse mechanisms are likely to drive probiotic benefits to host health. In some cases, such as production of antimicrobial products and cross-feeding other resident microbes, these mechanisms are driven directly by interactions with the resident microbiota. In other cases, such as direct interaction with immune cells, their effects might be directly via interaction with host cells. Overall, clinical benefits delivered by probiotics could result from the combined action of several mechanisms.

GABA, gamma amino butyric acid.

\section{Figure 2. Identified mechanisms of action of prebiotics}

The premise is that prebiotics enter the gut and are selectively utilized. This step increases bacterial growth and functionality of specific genera or species. As a result of either or both of these effects, health benefits can then accrue. Fecal bulking and improved bowel habits occurs due to microbial growth. Immune regulation can be influenced by increased biomass and cell wall components of the bacteria. Metabolic products include organic acids, which lowers intestinal $\mathrm{pH}$ and have concomitant effects upon microbial pathogens and mineral absorption. Metabolic products can also influence epithelial integrity and hormonal regulation. Bacteria that respond to prebiotic intake can influence the microbiota composition through elaboration of antimicrobial agents (e.g. peptides) and competitive interactions, possibly reducing infections and bacteria containing LPS.

GLP, glucagon like peptide; IL - interleukin; LPS, lipopolysaccharide; PYY, peptide YY; TGF, transforming growth factor; Th1, type 1 T-helper cell, type 1; Th2, type 2-T helper cell; Tr, regulatory $\mathrm{T}$ cell. 


\section{Literature Cited}

1 Food and Agriculture Organization of the United Nations and World Health Organization. Health and nutritional properties of probiotics in food including powder milk with live lactic acid bacteria, $<$ http://www.fao.org/3/a-a0512e.pdf> (2001).

2 Hill, C. et al. Expert consensus document. The International Scientific Association for Probiotics and Prebiotics consensus statement on the scope and appropriate use of the term probiotic. Nat Rev Gastroenterol Hepatol 11, 506-514, doi:10.1038/nrgastro.2014.66 (2014).

3 Rook, G., Backhed, F., Levin, B. R., McFall-Ngai, M. J. \& McLean, A. R. Evolution, human-microbe interactions, and life history plasticity. Lancet 390, 521-530, doi:10.1016/S0140-6736(17)30566-4 (2017).

4 Reid, G. et al. Expanding the reach of probiotics through social enterprises. Benef Microbes 9, 707-715, doi:10.3920/BM2018.0015 (2018).

5 Gibson, G. R. \& Roberfroid, M. B. Dietary modulation of the human colonic microbiota: introducing the concept of prebiotics. J Nutr 125, 1401-1412, doi:10.1093/jn/125.6.1401 (1995).

6 Gibson, G. R. et al. Expert consensus document: The International Scientific Association for Probiotics and Prebiotics (ISAPP) consensus statement on the definition and scope of prebiotics. Nat Rev Gastroenterol Hepatol 14, 491-502, doi:10.1038/nrgastro.2017.75 (2017).

7 Collins, S. L. et al. Promising prebiotic candidate established by evaluation of lactitol, lactulose, raffinose, and oligofructose for maintenance of a Lactobacillus-dominated vaginal microbiota. Appl Environ Microbiol 84, doi:10.1128/AEM.02200-17 (2018).

8 Rodriguez, J. M. et al. The composition of the gut microbiota throughout life, with an emphasis on early life. Microb Ecol Health Dis 26, 26050, doi:10.3402/mehd.v26.26050 (2015).

9 Donaldson, G. P., Lee, S. M. \& Mazmanian, S. K. Gut biogeography of the bacterial microbiota. Nat Rev Microbiol 14, 20-32, doi:10.1038/nrmicro3552 (2016).

10 Rowland, I. et al. Gut microbiota functions: metabolism of nutrients and other food components. Eur J Nutr 57, 1-24, doi:10.1007/s00394-0171445-8 (2018).

11 Thursby, E. \& Juge, N. Introduction to the human gut microbiota. Biochem J 474, 1823-1836, doi:10.1042/BCJ20160510 (2017).

12 Fava, F. et al. The type and quantity of dietary fat and carbohydrate alter faecal microbiome and short-chain fatty acid excretion in a metabolic syndrome 'at-risk' population. Int J Obes (Lond) 37, 216-223, doi:10.1038/ijo.2012.33 (2013).

13 Dicks, L. M. T., Geldenhuys, J., Mikkelsen, L. S., Brandsborg, E. \& Marcotte, H. Our gut microbiota: a long walk to homeostasis. Benef Microbes 9, 3-20, doi:10.3920/BM2017.0066 (2018).

14 Dethlefsen, L. \& Relman, D. A. Incomplete recovery and individualized responses of the human distal gut microbiota to repeated antibiotic perturbation. Proc Natl Acad Sci U S A 108 Suppl 1, 4554-4561, doi:10.1073/pnas.1000087107 (2011). 
15 Gagliardi, A. et al. Rebuilding the gut microbiota ecosystem. Int J Environ Res Public Health 15, doi:10.3390/ijerph15081679 (2018).

16 Hatton, G. B., Madla, C. M., Rabbie, S. C. \& Basit, A. W. All disease begins in the gut: Influence of gastrointestinal disorders and surgery on oral drug performance. Int J Pharm 548, 408-422, doi:10.1016/j.ijpharm.2018.06.054 (2018).

17 John, G. K. et al. Dietary alteration of the gut microbiome and its impact on weight and fat mass: A systematic review and meta-analysis. Genes (Basel) 9, doi:10.3390/genes9030167 (2018).

18 Yoshida, N., Yamashita, T. \& Hirata, K. I. Gut microbiome and cardiovascular diseases. Diseases 6, doi:10.3390/diseases6030056 (2018).

19 Hansen, L. B. S. et al. A low-gluten diet induces changes in the intestinal microbiome of healthy Danish adults. Nat Commun 9, 4630, doi:10.1038/s41467-018-07019-x (2018).

20 Parker, R. B. Probiotics, the other half of the antibiotic story. Anim Nutr Health 29, 4-8 (1974).

21 Havenaar, R. \& Huis In't Veld, J. M. J. in Lactic Acid Bacteria in Health and Disease Vol. 1 (ed B.J.B. Wood) 151-170 (Elsevier Applied Science Publishers, 1992).

$22 \mathrm{Ng}$, S. C. et al. Immunosuppressive effects via human intestinal dendritic cells of probiotic bacteria and steroids in the treatment of acute ulcerative colitis. Inflamm Bowel Dis 16, 1286-1298, doi:10.1002/ibd.21222 (2010).

23 Mujagic, Z. et al. The effects of Lactobacillus plantarum on small intestinal barrier function and mucosal gene transcription; a randomized doubleblind placebo controlled trial. Sci Rep 7, 40128, doi:10.1038/srep40128 (2017).

24 Del Piano, M. et al. The use of probiotics in healthy volunteers with evacuation disorders and hard stools: a double-blind, randomized, placebo-controlled study. J Clin Gastroenterol 44 Suppl 1, S30-34, doi:10.1097/MCG.0b013e3181ee31c3 (2010).

25 Reid, G., Gadir, A. A. \& Dhir, R. Probiotics: Reiterating what they are and what they are not. Front Microbiol 10, 424, doi:10.3389/fmicb.2019.00424 (2019).

26 Cabre, E. \& M, A. G. Probiotics for preventing relapse or recurrence in Crohn's disease involving the ileum: Are there reasons for failure? $\mathrm{J}$ Crohns Colitis 1, 47-52, doi:10.1016/j.crohns.2007.06.003 (2007).

27 Kelly, J. R. et al. Lost in translation? The potential psychobiotic Lactobacillus rhamnosus (JB-1) fails to modulate stress or cognitive performance in healthy male subjects. Brain Behav Immun 61, 50-59, doi:10.1016/j.bbi.2016.11.018 (2017).

28 Panigrahi, P. et al. A randomized synbiotic trial to prevent sepsis among infants in rural India. Nature 548, 407-412, doi:10.1038/nature23480 (2017).

29 Costeloe, K. et al. Bifidobacterium breve BBG-001 in very preterm infants: a randomised controlled phase 3 trial. Lancet 387, 649-660, doi:10.1016/S0140-6736(15)01027-2 (2016). 
30 Sorbara, M. T. \& Pamer, E. G. Interbacterial mechanisms of colonization resistance and the strategies pathogens use to overcome them. Mucosal Immunol, doi:10.1038/s41385-018-0053-0 (2018).

31 Chiu, L. et al. Protective microbiota: From localized to long-reaching coimmunity. Front Immunol 8, 1678, doi:10.3389/fimmu.2017.01678 (2017).

32 Maldonado-Gomez, M. X. et al. Stable engraftment of Bifidobacterium longum AH1206 in the human gut depends on individualized features of the resident microbiome. Cell Host Microbe 20, 515-526, doi:10.1016/j.chom.2016.09.001 (2016).

33 Murphy, R. et al. Eczema-protective probiotic alters infant gut microbiome functional capacity but not composition: sub-sample analysis from a RCT. Benef Microbes 10, 5-17, doi:10.3920/BM2017.0191 (2019).

34 Korpela, K. et al. Probiotic supplementation restores normal microbiota composition and function in antibiotic-treated and in caesarean-born infants. Microbiome 6, 182, doi:10.1186/s40168-018-0567-4 (2018).

35 Clarke, G. et al. Gut reactions: Breaking down xenobiotic-microbiome interactions. Pharmacol Rev 71, 198-224, doi:10.1124/pr.118.015768 (2019).

36 Klaenhammer, T. R., Kleerebezem, M., Kopp, M. V. \& Rescigno, M. The impact of probiotics and prebiotics on the immune system. Nat Rev Immunol 12, 728-734, doi:10.1038/nri3312 (2012).

37 Przemska-Kosicka, A. et al. Effect of a synbiotic on the response to seasonal influenza vaccination is strongly influenced by degree of immunosenescence. Immun Ageing 13, 6, doi:10.1186/s12979-016-00614 (2016).

38 Vitetta, L., Saltzman, E. T., Thomsen, M., Nikov, T. \& Hall, S. Adjuvant probiotics and the intestinal microbiome: enhancing vaccines and immunotherapy outcomes. Vaccines (Basel) 5, doi:10.3390/vaccines5040050 (2017).

39 Childs, C. E. et al. Xylo-oligosaccharides alone or in synbiotic combination with Bifidobacterium animalis subsp. lactis induce bifidogenesis and modulate markers of immune function in healthy adults: a double-blind, placebo-controlled, randomised, factorial cross-over study. Br J Nutr 111, 1945-1956, doi:10.1017/S0007114513004261 (2014).

40 Flint, H. J., Duncan, S. H., Scott, K. P. \& Louis, P. Links between diet, gut microbiota composition and gut metabolism. Proc Nutr Soc 74, 13-22, doi:10.1017/S0029665114001463 (2015).

41 Aoudia, N. et al. Biofilms of Lactobacillus plantarum and Lactobacillus fermentum: Effect on stress responses, antagonistic effects on pathogen growth and immunomodulatory properties. Food Microbiol 53, 51-59, doi:10.1016/j.fm.2015.04.009 (2016).

42 Rios-Covian, D. et al. Intestinal short chain fatty acids and their link with diet and human health. Front Microbiol 7, 185, doi:10.3389/fmicb.2016.00185 (2016).

43 Canfora, E. E., Jocken, J. W. \& Blaak, E. E. Short-chain fatty acids in control of body weight and insulin sensitivity. Nat Rev Endocrinol 11, 577-591, doi:10.1038/nrendo.2015.128 (2015). 
44 Sanna, S. et al. Causal relationships among the gut microbiome, shortchain fatty acids and metabolic diseases. Nat Genet 51, 600-605, doi:10.1038/s41588-019-0350-x (2019).

45 Stefan, N., Fritsche, A., Schick, F. \& Haring, H. U. Phenotypes of prediabetes and stratification of cardiometabolic risk. Lancet Diabetes Endocrinol 4, 789-798, doi:10.1016/S2213-8587(16)00082-6 (2016).

46 van Baarlen, P., Wells, J. M. \& Kleerebezem, M. Regulation of intestinal homeostasis and immunity with probiotic lactobacilli. Trends Immunol 34, 208-215, doi:10.1016/j.it.2013.01.005 (2013).

47 Hegarty, J. W., Guinane, C. M., Ross, R. P., Hill, C. \& Cotter, P. D. Bacteriocin production: a relatively unharnessed probiotic trait? F1000Res 5, 2587, doi:10.12688/f1000research.9615.1 (2016).

48 Mokoena, M. P. Lactic acid bacteria and their bacteriocins: Classification, biosynthesis and applications against uropathogens: A mini-review.

Molecules 22, doi:10.3390/molecules22081255 (2017).

49 Bali, V., Panesar, P. S., Bera, M. B. \& Kennedy, J. F. Bacteriocins: Recent trends and potential applications. Crit Rev Food Sci Nutr 56, 817-834, doi:10.1080/10408398.2012.729231 (2016).

50 Riviere, A., Selak, M., Lantin, D., Leroy, F. \& De Vuyst, L. Bifidobacteria and butyrate-producing colon bacteria: Importance and strategies for their stimulation in the human gut. Front Microbiol 7, 979, doi:10.3389/fmicb.2016.00979 (2016).

51 Abdulkadir, B. et al. Routine use of probiotics in preterm infants: Longitudinal impact on the microbiome and metabolome. Neonatology 109, 239-247, doi:10.1159/000442936 (2016).

52 Fang, H. R., Zhang, G. Q., Cheng, J. Y. \& Li, Z. Y. Efficacy of Lactobacillussupplemented triple therapy for Helicobacter pylori infection in children: a meta-analysis of randomized controlled trials. Eur J Pediatr 178, 7-16, doi:10.1007/s00431-018-3282-z (2019).

53 Sanders, M. E., Benson, A., Lebeer, S., Merenstein, D. J. \& Klaenhammer, T. R. Shared mechanisms among probiotic taxa: implications for general probiotic claims. Curr Opin Biotechnol 49, 207-216, doi:10.1016/j.copbio.2017.09.007 (2018).

54 Petrova, M. I. et al. Comparative genomic and phenotypic analysis of the vaginal probiotic Lactobacillus rhamnosus GR-1. Front Microbiol 9, 1278, doi:10.3389/fmicb.2018.01278 (2018).

55 La Fata, G., Weber, P. \& Mohajeri, M. H. Probiotics and the gut immune system: Indirect regulation. Probiotics Antimicrob Proteins 10, 11-21, doi:10.1007/s12602-017-9322-6 (2018).

56 Han, X. et al. Lactobacillus rhamnosus GG prevents epithelial barrier dysfunction induced by interferon-gamma and fecal supernatants from irritable bowel syndrome patients in human intestinal enteroids and colonoids. Gut Microbes 10, 59-76, doi:10.1080/19490976.2018.1479625 (2019).

57 Mack, D. R., Michail, S., Wei, S., McDougall, L. \& Hollingsworth, M. A. Probiotics inhibit enteropathogenic $E$. coli adherence in vitro by inducing intestinal mucin gene expression. Am J Physiol 276, G941-950 (1999).

58 Yan, F. et al. A Lactobacillus rhamnosus GG-derived soluble protein, p40, stimulates ligand release from intestinal epithelial cells to transactivate 
epidermal growth factor receptor. J Biol Chem 288, 30742-30751, doi:10.1074/jbc.M113.492397 (2013).

59 Stadlbauer, V. et al. Lactobacillus casei Shirota supplementation does not restore gut microbiota composition and gut barrier in metabolic syndrome: A randomized pilot study. PLoS One 10, e0141399, doi:10.1371/journal.pone.0141399 (2015).

60 Kim, N., Yun, M., Oh, Y. J. \& Choi, H. J. Mind-altering with the gut: Modulation of the gut-brain axis with probiotics. J Microbiol 56, 172-182, doi:10.1007/s12275-018-8032-4 (2018).

61 Janik, R. et al. Magnetic resonance spectroscopy reveals oral Lactobacillus promotion of increases in brain GABA, $\mathrm{N}$-acetyl aspartate and glutamate. Neuroimage 125, 988-995, doi:10.1016/j.neuroimage.2015.11.018 (2016).

62 Reid, G. Disentangling what we know about microbes and mental health. Front Endocrinol (Lausanne) 10, 81, doi:10.3389/fendo.2019.00081 (2019).

63 Liang, S. et al. Administration of Lactobacillus helveticus NS8 improves behavioral, cognitive, and biochemical aberrations caused by chronic restraint stress. Neuroscience 310, 561-577, doi:10.1016/j.neuroscience.2015.09.033 (2015).

64 Kotz, C. M., Furne, J. K., Savaiano, D. A. \& Levitt, M. D. Factors affecting the ability of a high beta-galactosidase yogurt to enhance lactose absorption. J Dairy Sci 77, 3538-3544, doi:10.3168/jds.S0022-0302(94)77296-9 (1994).

65 Costabile, A. et al. An in vivo assessment of the cholesterol-lowering efficacy of Lactobacillus plantarum ECGC 13110402 in normal to mildly hypercholesterolaemic adults. PLoS One 12, e0187964, doi:10.1371/journal.pone.0187964 (2017).

66 European Food Safety Authority Panel on Dietetic Products, N. a. A. Scientific Opinion on the substantiation of health claims related to live yoghurt cultures and improved lactose digestion (ID 1143, 2976) pursuant to Article 13(1) of Regulation (EC) No 1924/2006. EFSA J 8, 1763 (2010).

67 Li, D., Wang, P., Wang, P., Hu, X. \& Chen, F. The gut microbiota: A treasure for human health. Biotechnol Adv 34, 1210-1224, doi:10.1016/j.biotechadv.2016.08.003 (2016).

68 Kasubuchi, M., Hasegawa, S., Hiramatsu, T., Ichimura, A. \& Kimura, I. Dietary gut microbial metabolites, short-chain fatty acids, and host metabolic regulation. Nutrients 7, 2839-2849, doi:10.3390/nu7042839 (2015).

69 Verbeke, K. A. et al. Towards microbial fermentation metabolites as markers for health benefits of prebiotics. Nutr Res Rev 28, 42-66, doi:10.1017/S0954422415000037 (2015).

70 David, L. A. et al. Diet rapidly and reproducibly alters the human gut microbiome. Nature 505, 559-563, doi:10.1038/nature12820 (2014).

71 Fogliano, V. et al. In vitro bioaccessibility and gut biotransformation of polyphenols present in the water-insoluble cocoa fraction. Mol Nutr Food Res 55 Suppl 1, S44-55, doi:10.1002/mnfr.201000360 (2011). 
72 Falony, G. et al. In vitro kinetic analysis of fermentation of prebiotic inulin-type fructans by Bifidobacterium species reveals four different phenotypes. Appl Environ Microbiol 75, 454-461, doi:10.1128/AEM.01488-08 (2009).

73 Riviere, A., Selak, M., Geirnaert, A., Van den Abbeele, P. \& De Vuyst, L. Complementary mechanisms for degradation of inulin-type fructans and arabinoxylan oligosaccharides among bifidobacterial strains suggest bacterial cooperation. Appl Environ Microbiol 84, doi:10.1128/AEM.02893-17 (2018).

74 Flint, H. J., Scott, K. P., Duncan, S. H., Louis, P. \& Forano, E. Microbial degradation of complex carbohydrates in the gut. Gut Microbes 3, 289306, doi:10.4161/gmic.19897 (2012).

75 Hamaker, B. R. \& Tuncil, Y. E. A perspective on the complexity of dietary fiber structures and their potential effect on the gut microbiota. J Mol Biol 426, 3838-3850, doi:10.1016/j.jmb.2014.07.028 (2014).

76 Ze, X., Le Mougen, F., Duncan, S. H., Louis, P. \& Flint, H. J. Some are more equal than others: the role of "keystone" species in the degradation of recalcitrant substrates. Gut Microbes 4, 236-240, doi:10.4161/gmic.23998 (2013).

77 Ze, X., Duncan, S. H., Louis, P. \& Flint, H. J. Ruminococcus bromii is a keystone species for the degradation of resistant starch in the human colon. ISME J 6, 1535-1543, doi:10.1038/ismej.2012.4 (2012).

78 Hosseini, E., Grootaert, C., Verstraete, W. \& Van de Wiele, T. Propionate as a health-promoting microbial metabolite in the human gut. Nutr Rev 69, 245-258, doi:10.1111/j.1753-4887.2011.00388.x (2011).

79 Louis, P. \& Flint, H. J. Diversity, metabolism and microbial ecology of butyrate-producing bacteria from the human large intestine. FEMS Microbiol Lett 294, 1-8, doi:10.1111/j.1574-6968.2009.01514.x (2009).

80 Falony, G., Calmeyn, T., Leroy, F. \& De Vuyst, L. Coculture fermentations of Bifidobacterium species and Bacteroides thetaiotaomicron reveal a mechanistic insight into the prebiotic effect of inulin-type fructans. Appl Environ Microbiol 75, 2312-2319, doi:10.1128/AEM.02649-08 (2009).

81 Scott, K. P., Martin, J. C., Duncan, S. H. \& Flint, H. J. Prebiotic stimulation of human colonic butyrate-producing bacteria and bifidobacteria, in vitro. FEMS Microbiol Ecol 87, 30-40, doi:10.1111/1574-6941.12186 (2014).

82 Flint, H. J., Duncan, S. H. \& Louis, P. The impact of nutrition on intestinal bacterial communities. Curr Opin Microbiol 38, 59-65, doi:10.1016/j.mib.2017.04.005 (2017).

83 Chen, T. et al. Fiber-utilizing capacity varies in Prevotella- versus Bacteroides-dominated gut microbiota. Sci Rep 7, 2594, doi:10.1038/s41598-017-02995-4 (2017).

$84 \mathrm{Wu}, \mathrm{Q}$. et al. Fermentation properties of isomaltooligosaccharides are affected by human fecal enterotypes. Anaerobe 48, 206-214, doi:10.1016/j.anaerobe.2017.08.016 (2017).

85 Qin, J. et al. A human gut microbial gene catalogue established by metagenomic sequencing. Nature 464, 59-65, doi:10.1038/nature08821 (2010). 
86 Frank, D. N. et al. Molecular-phylogenetic characterization of microbial community imbalances in human inflammatory bowel diseases. Proc Natl Acad Sci U S A 104, 13780-13785, doi:10.1073/pnas.0706625104 (2007).

87 Larsen, N. et al. Gut microbiota in human adults with type 2 diabetes differs from non-diabetic adults. PLoS One 5, e9085, doi:10.1371/journal.pone.0009085 (2010).

88 Qin, J. et al. A metagenome-wide association study of gut microbiota in type 2 diabetes. Nature 490, 55-60, doi:10.1038/nature11450 (2012).

89 Karlsson, F. H. et al. Gut metagenome in European women with normal, impaired and diabetic glucose control. Nature 498, 99-103, doi:10.1038/nature12198 (2013).

90 Carroll, I. M., Chang, Y. H., Park, J., Sartor, R. B. \& Ringel, Y. Luminal and mucosal-associated intestinal microbiota in patients with diarrheapredominant irritable bowel syndrome. Gut Pathog 2, 19, doi:10.1186/1757-4749-2-19 (2010).

91 Krogius-Kurikka, L. et al. Microbial community analysis reveals high level phylogenetic alterations in the overall gastrointestinal microbiota of diarrhoea-predominant irritable bowel syndrome sufferers. $B M C$ Gastroenterol 9, 95, doi:10.1186/1471-230X-9-95 (2009).

92 Turnbaugh, P. J. et al. An obesity-associated gut microbiome with increased capacity for energy harvest. Nature 444, 1027-1031, doi:10.1038/nature05414 (2006).

93 Zhang, H. et al. Human gut microbiota in obesity and after gastric bypass. Proc Natl Acad Sci U S A 106, 2365-2370, doi:10.1073/pnas.0812600106 (2009).

94 Ha, C. W., Lam, Y. Y. \& Holmes, A. J. Mechanistic links between gut microbial community dynamics, microbial functions and metabolic health. World J Gastroenterol 20, 16498-16517, doi:10.3748/wjg.v20.i44.16498 (2014).

95 Moya, A. \& Ferrer, M. Functional redundancy-induced stability of gut microbiota subjected to disturbance. Trends Microbiol 24, 402-413, doi:10.1016/j.tim.2016.02.002 (2016).

96 Fooks, L. J. \& Gibson, G. R. In vitro investigations of the effect of probiotics and prebiotics on selected human intestinal pathogens. FEMS Microbiol Ecol 39, 67-75, doi:10.1111/j.1574-6941.2002.tb00907.x (2002).

97 Tzortzis, G., Baillon, M. L., Gibson, G. R. \& Rastall, R. A. Modulation of antipathogenic activity in canine-derived Lactobacillus species by carbohydrate growth substrate. J Appl Microbiol 96, 552-559 (2004).

98 Vulevic, J., Drakoularakou, A., Yaqoob, P., Tzortzis, G. \& Gibson, G. R. Modulation of the fecal microflora profile and immune function by a novel trans-galactooligosaccharide mixture (B-GOS) in healthy elderly volunteers. Am J Clin Nutr 88, 1438-1446, doi:10.3945/ajcn.2008.26242 (2008).

99 Vulevic, J. et al. Influence of galacto-oligosaccharide mixture (B-GOS) on gut microbiota, immune parameters and metabonomics in elderly persons. Br J Nutr 114, 586-595, doi:10.1017/S0007114515001889 (2015). 
100 Moro, G. et al. A mixture of prebiotic oligosaccharides reduces the incidence of atopic dermatitis during the first six months of age. Arch Dis Child 91, 814-819, doi:10.1136/adc.2006.098251 (2006).

101 Ivakhnenko, O. S. \& Nyankovskyy, S. L. Effect of the specific infant formula mixture of oligosaccharides on local immunity and development of allergic and infectious disease in young children: randomized study. Pediatria. Polska 88, 398-404 (2013).

102 Arslanoglu, S. et al. Early neutral prebiotic oligosaccharide supplementation reduces the incidence of some allergic manifestations in the first 5 years of life. J Biol Regul Homeost Agents 26, 49-59 (2012).

103 Diaz de Barboza, G., Guizzardi, S. \& Tolosa de Talamoni, N. Molecular aspects of intestinal calcium absorption. World J Gastroenterol 21, 71427154, doi:10.3748/wjg.v21.i23.7142 (2015).

104 Goss, S. L., Lemons, K. A., Kerstetter, J. E. \& Bogner, R. H. Determination of calcium salt solubility with changes in $\mathrm{pH}$ and $\mathrm{P}(\mathrm{CO}(2))$, simulating varying gastrointestinal environments. J Pharm Pharmacol 59, 14851492, doi:10.1211/jpp.59.11.0004 (2007).

105 Abrams, S. A., Griffin, I. J., Hawthorne, K. M. \& Ellis, K. J. Effect of prebiotic supplementation and calcium intake on body mass index. J Pediatr 151, 293-298, doi:10.1016/j.jpeds.2007.03.043 (2007).

106 Abrams, S. A., Griffin, I. J. \& Hawthorne, K. M. Young adolescents who respond to an inulin-type fructan substantially increase total absorbed calcium and daily calcium accretion to the skeleton. J Nutr 137, 2524S2526S, doi:10.1093/jn/137.11.2524S (2007).

107 Whisner, C. M. et al. Galacto-oligosaccharides increase calcium absorption and gut bifidobacteria in young girls: a double-blind cross-over trial. $\mathrm{Br} \mathrm{J}$ Nutr 110, 1292-1303, doi:10.1017/S000711451300055X (2013).

108 Chonan, O., Matsumoto, K. \& Watanuki, M. Effect of galactooligosaccharides on calcium absorption and preventing bone loss in ovariectomized rats. Biosci Biotechnol Biochem 59, 236-239, doi:10.1271/bbb.59.236 (1995).

109 Kanauchi, O., Andoh, A. \& Mitsuyama, K. Effects of the modulation of microbiota on the gastrointestinal immune system and bowel function. $J$ Agric Food Chem 61, 9977-9983, doi:10.1021/jf402441f (2013).

110 Hurst, N. R., Kendig, D. M., Murthy, K. S. \& Grider, J. R. The short chain fatty acids, butyrate and propionate, have differential effects on the motility of the guinea pig colon. Neurogastroenterol Motil 26, 1586-1596, doi:10.1111/nmo.12425 (2014).

111 Lamsal, B. P. Production, health aspects and potential food uses of dairy prebiotic galactooligosaccharides. J Sci Food Agric 92, 2020-2028, doi:10.1002/jsfa.5712 (2012).

112 Hager, A.-S. et al. Influence of the soluble fibres inulin and oat $\beta$-glucan on quality of dough and bread. Eur Food Res Technol 232, 405-413 (2011).

113 Collado Yurrita, L., San Mauro Martin, I., Ciudad-Cabanas, M. J., CallePuron, M. E. \& Hernandez Cabria, M. Effectiveness of inulin intake on indicators of chronic constipation; a meta-analysis of controlled randomized clinical trials. Nutr Hosp 30, 244-252, doi:10.3305/nh.2014.30.2.7565 (2014). 
114 Buddington, R. K., Kapadia, C., Neumer, F. \& Theis, S. Oligofructose provides laxation for irregularity associated with low fiber intake. Nutrients 9, doi:10.3390/nu9121372 (2017).

115 Krumbeck, J. A. et al. Probiotic Bifidobacterium strains and galactooligosaccharides improve intestinal barrier function in obese adults but show no synergism when used together as synbiotics. Microbiome 6, 121, doi:10.1186/s40168-018-0494-4 (2018).

116 Cani, P. D. et al. Metabolic endotoxemia initiates obesity and insulin resistance. Diabetes 56, 1761-1772, doi:10.2337/db06-1491 (2007).

117 Cani, P. D. et al. Changes in gut microbiota control metabolic endotoxemia-induced inflammation in high-fat diet-induced obesity and diabetes in mice. Diabetes 57, 1470-1481, doi:10.2337/db07-1403 (2008).

118 Cani, P. D. et al. Changes in gut microbiota control inflammation in obese mice through a mechanism involving GLP-2-driven improvement of gut permeability. Gut 58, 1091-1103, doi:10.1136/gut.2008.165886 (2009).

119 Kellow, N. J., Coughlan, M. T. \& Reid, C. M. Metabolic benefits of dietary prebiotics in human subjects: a systematic review of randomised controlled trials. Br J Nutr 111, 1147-1161, doi:10.1017/S0007114513003607 (2014).

120 Beserra, B. T. et al. A systematic review and meta-analysis of the prebiotics and synbiotics effects on glycaemia, insulin concentrations and lipid parameters in adult patients with overweight or obesity. Clin Nutr 34, 845-858, doi:10.1016/j.clnu.2014.10.004 (2015).

121 Liu, F., Prabhakar, M., Ju, J., Long, H. \& Zhou, H. W. Effect of inulin-type fructans on blood lipid profile and glucose level: a systematic review and meta-analysis of randomized controlled trials. Eur J Clin Nutr 71, 9-20, doi:10.1038/ejcn.2016.156 (2017).

122 Guo, Z. et al. Effects of inulin on the plasma lipid profile of normolipidemic and hyperlipidemic subjects: a meta-analysis of randomized controlled trials. Clin Lipidol 7, 215-222 (2012).

123 Vulevic, J., Juric, A., Tzortzis, G. \& Gibson, G. R. A mixture of transgalactooligosaccharides reduces markers of metabolic syndrome and modulates the fecal microbiota and immune function of overweight adults. J Nutr 143, 324-331, doi:10.3945/jn.112.166132 (2013).

124 Dewulf, E. M. et al. Insight into the prebiotic concept: lessons from an exploratory, double blind intervention study with inulin-type fructans in obese women. Gut 62, 1112-1121, doi:10.1136/gutjnl-2012-303304 (2013).

125 Bhatia, S. et al. Galacto-oligosaccharides may directly enhance intestinal barrier function through the modulation of goblet cells. Mol Nutr Food Res 59, 566-573, doi:10.1002/mnfr.201400639 (2015).

126 Akbari, P. et al. Characterizing microbiota-independent effects of oligosaccharides on intestinal epithelial cells: insight into the role of structure and size : Structure-activity relationships of non-digestible oligosaccharides. Eur J Nutr 56, 1919-1930, doi:10.1007/s00394-0161234-9 (2017). 
127 Neyrinck, A. M. et al. Intestinal sucrase as a novel target contributing to the regulation of glycemia by prebiotics. PLoS One 11, e0160488, doi:10.1371/journal.pone.0160488 (2016).

128 Stoddart, L. A., Smith, N. J. \& Milligan, G. International Union of Pharmacology. LXXI. Free fatty acid receptors FFA1, -2, and -3: pharmacology and pathophysiological functions. Pharmacol Rev 60, 405417, doi:10.1124/pr.108.00802 (2008).

129 Bolognini, D. et al. Chemogenetics defines receptor-mediated functions of short chain free fatty acids. Nat Chem Biol 15, 489-498, doi:10.1038/s41589-019-0270-1 (2019).

130 Chambers, E. S., Morrison, D. J. \& Frost, G. Control of appetite and energy intake by SCFA: what are the potential underlying mechanisms? Proc Nutr Soc 74, 328-336, doi:10.1017/S0029665114001657 (2015).

131 Mithieux, G. Metabolic effects of portal vein sensing. Diabetes Obes Metab 16 Suppl 1, 56-60, doi:10.1111/dom.12338 (2014).

132 Frost, G. et al. The short-chain fatty acid acetate reduces appetite via a central homeostatic mechanism. Nat Commun 5, 3611, doi:10.1038/ncomms4611 (2014).

133 Jackson, S. A. et al. Improving end-user trust in the quality of commercial probiotic products. Front Microbiol 10, 739, doi:10.3389/fmicb.2019.00739 (2019).

134 AlFaleh, K. \& Anabrees, J. Probiotics for prevention of necrotizing enterocolitis in preterm infants. Cochrane Database Syst Rev, CD005496, doi:10.1002/14651858.CD005496.pub4 (2014).

135 Vanderhoof, J. A. et al. Lactobacillus GG in the prevention of antibioticassociated diarrhea in children. J Pediatr 135, 564-568 (1999).

136 Szajewska, H., Albrecht, P. \& Topczewska-Cabanek, A. Randomized, double-blind, placebo-controlled trial: effect of Lactobacillus GG supplementation on Helicobacter pylori eradication rates and side effects during treatment in children. J Pediatr Gastroenterol Nutr 48, 431-436 (2009).

137 Goldenberg, J. Z. et al. Probiotics for the prevention of pediatric antibioticassociated diarrhea. Cochrane Database Syst Rev, CD004827, doi:10.1002/14651858.CD004827.pub4 (2015).

138 Eskesen, D. et al. Effect of the probiotic strain Bifidobacterium animalis subsp. lactis, BB-12(R), on defecation frequency in healthy subjects with low defecation frequency and abdominal discomfort: a randomised, double-blind, placebo-controlled, parallel-group trial. Br J Nutr 114, 1638-1646, doi:10.1017/S0007114515003347 (2015).

139 Yang, Y. X. et al. Effect of a fermented milk containing Bifidobacterium lactis DN-173010 on Chinese constipated women. World J Gastroenterol 14, 6237-6243, doi:10.3748/wjg.14.6237 (2008).

140 Sung, V. et al. Lactobacillus reuteri to treat infant colic: A meta-analysis. Pediatrics 141, doi:10.1542/peds.2017-1811 (2018).

141 Mardini, H. E. \& Grigorian, A. Y. Probiotic mix VSL\#3 is effective adjunctive therapy for mild to moderately active ulcerative colitis: a metaanalysis. Inflamm Bowel Dis 20, 1562-1567, doi:10.1097/MIB.0000000000000084 (2014). 
142 Whorwell, P. J. et al. Efficacy of an encapsulated probiotic Bifidobacterium infantis 35624 in women with irritable bowel syndrome. Am J Gastroenterol 101, 1581-1590, doi:10.1111/j.1572-0241.2006.00734.x (2006).

143 Szajewska, H. et al. Systematic review with meta-analysis: Lactobacillus rhamnosus GG for treating acute gastroenteritis in children - a 2019 update. Aliment Pharmacol Ther 49, 1376-1384, doi:10.1111/apt.15267 (2019).

144 Goldenberg, J. Z. et al. Probiotics for the prevention of Clostridium difficileassociated diarrhea in adults and children. Cochrane Database Syst Rev 12, CD006095, doi:10.1002/14651858.CD006095.pub4 (2017).

145 King, S. et al. Does probiotic consumption reduce antibiotic utilization for common acute infections? A systematic review and meta-analysis. Eur J Public Health 29, 494-499, doi:10.1093/eurpub/cky185 (2019).

146 Cruchet, S. et al. The use of probiotics in pediatric gastroenterology: a review of the literature and recommendations by Latin-American experts. Paediatr Drugs 17, 199-216, doi:10.1007/s40272-015-0124-6 (2015).

147 Cameron, D. et al. Probiotics for gastrointestinal disorders: Proposed recommendations for children of the Asia-Pacific region. World J Gastroenterol 23, 7952-7964, doi:10.3748/wjg.v23.i45.7952 (2017).

148 Hao, Q., Dong, B. R. \& Wu, T. Probiotics for preventing acute upper respiratory tract infections. Cochrane Database Syst Rev, CD006895, doi:10.1002/14651858.CD006895.pub3 (2015).

149 King, S., Glanville, J., Sanders, M. E., Fitzgerald, A. \& Varley, D. Effectiveness of probiotics on the duration of illness in healthy children and adults who develop common acute respiratory infectious conditions: a systematic review and meta-analysis. Br J Nutr 112, 41-54, doi:10.1017/S0007114514000075 (2014).

150 Yang, L. et al. Inflammation and intestinal metaplasia of the distal esophagus are associated with alterations in the microbiome.

Gastroenterology 137, 588-597, doi:10.1053/j.gastro.2009.04.046 (2009).

151 Szymanski, H. \& Szajewska, H. Lack of efficacy of Lactobacillus reuteri DSM 17938 for the treatment of acute gastroenteritis: A randomized controlled trial. Pediatr Infect Dis J, doi:10.1097/INF.0000000000002355 (2019).

152 van den Akker, C. H. P. et al. Probiotics for preterm infants: A strainspecific systematic review and network meta-analysis. J Pediatr Gastroenterol Nutr 67, 103-122, doi:10.1097/MPG.0000000000001897 (2018).

153 Arslanoglu, S., Moro, G. E. \& Boehm, G. Early supplementation of prebiotic oligosaccharides protects formula-fed infants against infections during the first 6 months of life. J Nutr 137, 2420-2424, doi:10.1093/jn/137.11.2420 (2007).

154 Arslanoglu, S. et al. Early dietary intervention with a mixture of prebiotic oligosaccharides reduces the incidence of allergic manifestations and infections during the first two years of life. J Nutr 138, 1091-1095, doi:10.1093/jn/138.6.1091 (2008).

155 Boehm, G. et al. Prebiotics in infant formulas. J Clin Gastroenterol 38, S7679 (2004). 
156 Shahramian, I. et al. The effects of prebiotic supplementation on weight gain, diarrhoea, constipation, fever and respiratory tract infections in the first year of life. J Paediatr Child Health 54, 875-880, doi:10.1111/jpc.13906 (2018).

157 Drakoularakou, A., Tzortzis, G., Rastall, R. A. \& Gibson, G. R. A doubleblind, placebo-controlled, randomized human study assessing the capacity of a novel galacto-oligosaccharide mixture in reducing travellers' diarrhoea. Eur J Clin Nutr 64, 146-152, doi:10.1038/ejcn.2009.120 (2010).

158 Micka, A., Siepelmeyer, A., Holz, A., Theis, S. \& Schon, C. Effect of consumption of chicory inulin on bowel function in healthy subjects with constipation: a randomized, double-blind, placebo-controlled trial. Int J Food Sci Nutr 68, 82-89, doi:10.1080/09637486.2016.1212819 (2017).

159 European Food Safety Authority Panel on Dietetic Products, N. a. A. Scientific Opinion on the substantiation of a health claim related to "native chicory inulin" and maintenance of normal defecation by increasing stool frequency pursuant to Article 13.5 of Regulation (EC) No 1924/2006. EFSA J. 13, 3951 (2015).

160 Hume, M. P., Nicolucci, A. C. \& Reimer, R. A. Prebiotic supplementation improves appetite control in children with overweight and obesity: a randomized controlled trial. Am J Clin Nutr 105, 790-799, doi:10.3945/ajcn.116.140947 (2017).

161 Nicolucci, A. C. et al. Prebiotics reduce body fat and alter intestinal microbiota in children who are overweight or with obesity. Gastroenterology 153, 711-722, doi:10.1053/j.gastro.2017.05.055 (2017).

162 Pol, K., de Graaf, C., Meyer, D. \& Mars, M. The efficacy of daily snack replacement with oligofructose-enriched granola bars in overweight and obese adults: a 12-week randomised controlled trial. Br J Nutr 119, 10761086, doi:10.1017/S0007114518000211 (2018).

163 Liber, A. \& Szajewska, H. Effect of oligofructose supplementation on body weight in overweight and obese children: a randomised, double-blind, placebo-controlled trial. Br J Nutr 112, 2068-2074, doi:10.1017/S0007114514003110 (2014).

164 European Food Safety Authority Panel on Dietetic Products. A. Scientific opinion on the substantiation of a health claim related to non-digestible carbohydrates and a reduction of post-prandial glycaemic responses pursuant to Article 13(5) of Regulation (EC) No 1924/2006. EFSA J. 12, 3513 (2015).

165 Lightowler, H., Thondre, S., Holz, A. \& Theis, S. Replacement of glycaemic carbohydrates by inulin-type fructans from chicory (oligofructose, inulin) reduces the postprandial blood glucose and insulin response to foods: report of two double-blind, randomized, controlled trials. Eur J Nutr 57, 1259-1268, doi:10.1007/s00394-017-1409-z (2018).

166 Olbjorn, C. et al. Fecal microbiota profiles in treatment-naive pediatric inflammatory bowel disease - associations with disease phenotype, treatment, and outcome. Clin Exp Gastroenterol 12, 37-49, doi:10.2147/CEG.S186235 (2019). 
167 Backhed, F. et al. Defining a healthy human gut microbiome: current concepts, future directions, and clinical applications. Cell Host Microbe 12, 611-622, doi:10.1016/j.chom.2012.10.012 (2012).

168 Dey, M. Toward a personalized approach in prebiotics research. Nutrients 9, doi:10.3390/nu9020092 (2017).

169 Healey, G. et al. Habitual dietary fibre intake influences gut microbiota response to an inulin-type fructan prebiotic: a randomised, double-blind, placebo-controlled, cross-over, human intervention study. Br J Nutr 119, 176-189, doi:10.1017/S0007114517003440 (2018).

170 Tandon, D. et al. A prospective randomized, double-blind, placebocontrolled, dose-response relationship study to investigate efficacy of fructo-oligosaccharides (FOS) on human gut microflora. Sci Rep 9, 5473, doi:10.1038/s41598-019-41837-3 (2019).

171 Bian, G. et al. The gut microbiota of healthy aged Chinese is similar to that of the healthy young. $m$ Sphere 2 , doi:10.1128/mSphere.00327-17 (2017).

172 Gloor, G. B., Macklaim, J. M., Pawlowsky-Glahn, V. \& Egozcue, J. J. Microbiome datasets are compositional: And this is not optional. Front Microbiol 8, 2224, doi:10.3389/fmicb.2017.02224 (2017).

173 Yatsunenko, T. et al. Human gut microbiome viewed across age and geography. Nature 486, 222-227, doi:10.1038/nature11053 (2012).

174 Marques, T. M. et al. Programming infant gut microbiota: influence of dietary and environmental factors. Curr Opin Biotechnol 21, 149-156, doi:10.1016/j.copbio.2010.03.020 (2010).

175 Claesson, M. J. et al. Gut microbiota composition correlates with diet and health in the elderly. Nature 488, 178-184, doi:10.1038/nature11319 (2012).

176 Clarke, S. F. et al. Exercise and associated dietary extremes impact on gut microbial diversity. Gut 63, 1913-1920, doi:10.1136/gutjnl-2013-306541 (2014).

177 Engen, P. A., Green, S. J., Voigt, R. M., Forsyth, C. B. \& Keshavarzian, A. The gastrointestinal microbiome: Alcohol effects on the composition of intestinal microbiota. Alcohol Res 37, 223-236 (2015).

178 Jostins, L. et al. Host-microbe interactions have shaped the genetic architecture of inflammatory bowel disease. Nature 491, 119-124, doi:10.1038/nature11582 (2012).

179 Picoraro, J. A. \& LeLeiko, N. S. Omes of inflammatory bowel disease: A primer for clinicians. J Pediatr Gastroenterol Nutr 66, 374-377, doi:10.1097/MPG.0000000000001844 (2018).

180 Weiser, M. et al. Molecular classification of Crohn's disease reveals two clinically relevant subtypes. Gut 67, 36-42, doi:10.1136/gutjnl-2016312518 (2018).

181 Bourreille, A. et al. Saccharomyces boulardii does not prevent relapse of Crohn's disease. Clin Gastroenterol Hepatol 11, 982-987, doi:10.1016/j.cgh.2013.02.021 (2013).

182 Van Gossum, A. et al. Multicenter randomized-controlled clinical trial of probiotics (Lactobacillus johnsonii, LA1) on early endoscopic recurrence of Crohn's disease after lleo-caecal resection. Inflamm Bowel Dis 13, 135142, doi:10.1002/ibd.20063 (2007). 
183 Tursi, A. et al. Treatment of relapsing mild-to-moderate ulcerative colitis with the probiotic VSL\#3 as adjunctive to a standard pharmaceutical treatment: a double-blind, randomized, placebo-controlled study. Am J Gastroenterol 105, 2218-2227, doi:10.1038/ajg.2010.218 (2010).

184 O'Toole, P. W., Marchesi, J. R. \& Hill, C. Next-generation probiotics: the spectrum from probiotics to live biotherapeutics. Nat Microbiol 2, 17057, doi:10.1038/nmicrobiol.2017.57 (2017).

185 Ridaura, V. K. et al. Gut microbiota from twins discordant for obesity modulate metabolism in mice. Science 341, 1241214, doi:10.1126/science.1241214 (2013).

186 van Nood, E. et al. Duodenal infusion of donor feces for recurrent Clostridium difficile. $N$ Engl J Med 368, 407-415, doi:10.1056/NEJMoa1205037 (2013).

187 Lee, C. H. et al. Frozen vs fresh fecal microbiota transplantation and clinical resolution of diarrhea in patients with recurrent Clostridium difficile infection: A randomized clinical trial. JAMA 315, 142-149, doi:10.1001/jama.2015.18098 (2016).

188 Kelly, C. R. et al. Effect of fecal microbiota transplantation on recurrence in multiply recurrent Clostridium difficile infection: A randomized trial.

Ann Intern Med 165, 609-616, doi:10.7326/M16-0271 (2016).

189 Halkjaer, S. I. et al. Faecal microbiota transplantation alters gut microbiota in patients with irritable bowel syndrome: results from a randomised, double-blind placebo-controlled study. Gut 67, 2107-2115, doi:10.1136/gutjnl-2018-316434 (2018).

190 Delaune, V. et al. Fecal microbiota transplantation: a promising strategy in preventing the progression of non-alcoholic steatohepatitis and improving the anti-cancer immune response. Expert Opin Biol Ther 18, 1061-1071, doi:10.1080/14712598.2018.1518424 (2018).

191 Moayyedi, P. et al. Fecal microbiota transplantation induces remission in patients with active ulcerative colitis in a randomized controlled trial. Gastroenterology 149, 102-109 e106, doi:10.1053/j.gastro.2015.04.001 (2015).

192 Gupta, S., Allen-Vercoe, E. \& Petrof, E. O. Fecal microbiota transplantation: in perspective. Therap Adv Gastroenterol 9, 229-239, doi:10.1177/1756283X15607414 (2016).

193 Reid, G. et al. How do probiotics and prebiotics function at distant sites? Benef Microbes 8, 521-533, doi:10.3920/BM2016.0222 (2017).

194 Hiippala, K. et al. The potential of gut commensals in reinforcing intestinal barrier function and alleviating inflammation. Nutrients $\mathbf{1 0}$, doi:10.3390/nu10080988 (2018).

195 Crusell, M. K. W. et al. Gestational diabetes is associated with change in the gut microbiota composition in third trimester of pregnancy and postpartum. Microbiome 6, 89, doi:10.1186/s40168-018-0472-x (2018).

196 Cousin, F. J. et al. The probiotic Propionibacterium freudenreichii as a new adjuvant for TRAIL-based therapy in colorectal cancer. Oncotarget 7, 7161-7178, doi:10.18632/oncotarget.6881 (2016).

197 Zullo, B. A. \& Ciafardini, G. Evaluation of physiological properties of yeast strains isolated from olive oil and their in vitro probiotic trait. Food Microbiol 78, 179-187, doi:10.1016/j.fm.2018.10.016 (2019). 
198 Gonzalez-Rodriguez, I. et al. Catabolism of glucose and lactose in Bifidobacterium animalis subsp. lactis, studied by 13C Nuclear Magnetic Resonance. Appl Environ Microbiol 79, 7628-7638, doi:10.1128/AEM.02529-13 (2013).

199 Kostinek, M. et al. Characterisation and biochemical properties of predominant lactic acid bacteria from fermenting cassava for selection as starter cultures. Int J Food Microbiol 114, 342-351, doi:10.1016/j.ijfoodmicro.2006.09.029 (2007).

200 Hancock, T., Capon, A., Dooris, M. \& Patrick, R. One planet regions: planetary health at the local level. Lancet Planet Health 1, e92-e93, doi:10.1016/S2542-5196(17)30044-X (2017).

201 Garchitorena, A. et al. Disease ecology, health and the environment: a framework to account for ecological and socio-economic drivers in the control of neglected tropical diseases. Philos Trans $R$ Soc Lond B Biol Sci 372, doi:10.1098/rstb.2016.0128 (2017). 